\title{
On Facilitating Regional Integration and Economic Development with Collaborative Technologies in the South Pacific
}

\author{
Acklesh Prasad \\ Queensland University of Technology \\ acklesh.prasad@qut.edu.au \\ Glen Finau \\ University of the South Pacific \\ finau g@usp.ac.fj \\ Jale Samuwai \\ University of the South Pacific \\ samuwai ¡@usp.ac.fj \\ Biman Prasad \\ University of the South Pacific \\ prasad bc@usp.ac.fj \\ Peter Green \\ University of Queensland \\ p.green@business.uq.edu.au
}

\begin{abstract}
The current global economic instability and the vulnerability of small island nations are providing the impetus for greater integration between the countries of the South Pacific region. This exercise is critical for their survival in today's turbulent economic environment. Past efforts of regional integration in the South Pacific have not been very successful. Reasons attributed to this outcome include issues related to damage of sovereignty, and lack of a shared integration infrastructure. Today, the IT resources with collaborative capacities provide the opportunity to develop a shared IT infrastructure to facilitate integration in the South Pacific. In an attempt to develop a model of regional integration with an IT-backed infrastructure, we identify and report on the antecedents of the current stage of regional integration, and the stakeholders' perceived benefits of an IT resources backed regional integration in the South Pacific. Employing a case study based approach, the study finds that while most stakeholders were positive about the potential of IT-backed regional integration, significant challenges exist that hinder the realisation of this model. The study finds that facilitating IT-backed regional integration requires enabling IT infrastructure, equitable IT development in the region, greater awareness on the potential of the modern IT resources, market liberalisation of the information and telecommunications sector and greater political support for IT initiatives.
\end{abstract}

Keywords: Regional integration, IT-backed regional integration, Web 2.0 tools, cloud computing resources, developing economies, South Pacific, collaborative technologies, ICT4D 


\section{Introduction}

In this study, we discuss factors that could lead to sustainable regional integration in the South Pacific. We do this by reporting on the antecedents of the current state of regional integration efforts in the South Pacific. We also report on the perceptions of the stakeholders on the approaches to, and the benefits of IT resource backed integration in this region. The outcome of this research will provide important insights in suggesting an IT resources backed regional integration model for the South Pacific.

Regional integration is a process in which countries enter into an agreement to enhance regional cooperation and development (Lee et al., 2009). IT resource fbacked regional integration relates to the use of collaborative IT resources to develop an integration infrastructure, which includes use of the Internet and Web 2.0 technologies. Regional integration agreements could be both economic and political. However, regional integration agreements have generally become a political economy initiative where commercial purposes are the means to achieve broader socio-political and security objectives (Akpan-Obong et al., 2009). Popularised in the 1980s, today all countries in the world are part of at least one regional bloc (Schiff et al., 2003).

Leveraging IT resources creates an environment conducive towards IT-enabled cross-border cooperation. Such an environment has the potential to accelerate regional integration initiatives through enhancing communication and collaboration, facilitating the creation, storage, sharing of knowledge, and engendering the ideal of a single unified community. We define this innovative form of IT-enabled regional integration as IT-backed regional integration. However, the use of IT tools in facilitating regional integration in the Pacific, unfortunately, is still nascent. The South Pacific region can benefit significantly from an IT-backed regional integration infrastructure. An IT-backed regional integration infrastructure requires multiple stages of investigation and development. Our eventual aim is to develop an IT-resources backed model of regional integration for the South Pacific. One of the first aspects of this model development exercise is the understanding of the environment in which the model would be adopted. To do this, we adopt a case study based approach to achieve two key outcomes. The first is obtaining the stakeholders' perceptions on the antecedents of the current stage of regional integration in the South Pacific. The second is obtaining the stakeholders' perceptions on the approaches to and the benefits of IT-backed regional integration infrastructure.

The primary data collection method in our research design was the semi-structured interview. We interviewed twenty five individuals from five South Pacific countries. These individuals occupied various positions of regional integration interest. Our detailed analysis of the interview data revealed that an impeding IT infrastructure, marginal human IT skills, disparity in level of development, monopolised communication infrastructure, and a frail political will as key antecedents of IT resource backed regional integration failures in the South Pacific. The interviewees also suggested that focus on enabling IT infrastructure, equitable IT development in the region, greater awareness on the potential of the modern IT resources, market liberalisation of the information and telecommunications sector, greater political support for IT initiatives in building a national and regional IT infrastructure are important in developing an IT-backed regional integration model for the South Pacific.

The rest of the paper proceeds as follows. The following section will discuss IT resource backed regional integration, the section following will present a brief overview of the South Pacific context. We then present the study's theoretical framework, and discuss the research design. The final sections of the paper discuss results of the study and provide implications and limitations of the research. 


\section{IT Resource Backed Regional Integration}

The relationship between IT resources and regional integration efforts in the developing economies is not well considered in the extant literature. A few, for example, Akpan-Obong and Parmentier (2009) review IT initiatives and the potential impact of these initiatives for regional integration in Africa and South America. Within these regions, IT and regional integration are perceived as integral to socioeconomic and political development. However, IT and regional integration are pursued as separate paths of development. Akpan-Obong and Parmentier (2009) also report that significant social and political impediments exist that hinder regional integration. While, the development of IT infrastructure alone is not sufficient to overcome these challenges, it has the potential to tame goal incongruence and political subjugation concerns of the developing countries. This situation is possible because appropriate use of IT resources, for example social networking and cloud computing resources, will provide a sense of shared ownership and independence to these countries.

The appeal of regional integration is particularly pertinent and timely for developing economies. The increasing connectedness and volatility of the global economy is affecting developing economies the most (The World Bank, 2009). Individually, developing economies lack the capacity to thrive in this type of environment. Collectively, however, these economies are able to better manage and direct their scarce resources to insulate from external economic shocks. Furthermore, regional integration efforts provide the impetus for economic growth and development. This outcome has been evident in Europe, and the Caribbean (Dion, 2004).

Scepticism about the Pacific Island Countries' (PICs) readiness to pursue regional integration has been highlighted by Powell (2005). However the member states' leaders of the Pacific Islands Forum Secretariat (PIFS) have attempted to face this challenge by endorsing "The Pacific Plan for Strengthening Regional Cooperation and Integration" in October 2005. This shows that despite the potential obstacles, regional integration is perceived as a desirable social good in the Pacific. However, the 2012 annual progress report shows that it still has a long way to go in achieving its goal of "enhancing and stimulating economic growth, sustainable development, good governance and security for Pacific countries through regionalism" (PIFS, 2007).

Past regional integration efforts of developing countries have largely been unsuccessful (Foroutan, 1993). Political reasons may contribute to some of these unsuccessful outcomes. However, given the distance among the countries of the Pacific region and the isolation of the smaller island states, a major hurdle to successful regional integration is the lack of a transparent, inclusive and dynamic communication and collaboration platform on which to engage on regional integration initiatives (Gnansounou et al., 2007). In order for a regional bloc to work, it has to give a voice to all its member states, not only the powerful ones. When even the remotest island states in the region are allowed or even encouraged to collaborate with the rest of the region, their input will undoubtedly enrich the discourse on how the region can actively participate in the global economy despite its size and distance. Furthermore, the island states' ability to express their views on an equal footing with the rest of the region would allay any fears that integration is merely a means for the more powerful members to achieve political, economic, or cultural subjugation. If this collaborative platform could be achieved, then the Pacific region could be united in its pursuit to pool resources and develop strategies for the benefit of all its member states.

In today's digital world, IT resources have the capacity to facilitate the development of the suggested regional integration platform. To do this, organisations in the South Pacific need to have the necessary infrastructure to provide a reliable yet affordable connection to the Internet. In April 2002, the PIFS released its 
Facilitating Regional Integration and Economic Development with Collaborative Technologies / Acklesh et al.

"Pacific Islands Information and Communication Technologies Policy and Strategic Plan" (PIIPP), which lists infrastructure development as one of its guiding principles. The authors of this plan acknowledged that access to the Internet was more expensive in the Pacific than the rest of the world (PIFS, 2002). A decade later, costs had become affordable for some countries like Fiji, where low-level use (2GB per month) costs USD 21.10 on average, but the same amount of data usage in Papua New Guinea remained exorbitant at USD 475.45 (Matthews, 2012). The PIFS is currently attempting to address the problem of making Internet access affordable and reliable through the implementation of its "Pacific Regional Digital Strategy" (PRDS), which was drafted back in 2009. The strategy at the regional level is to encourage investments in IT infrastructure by strengthening the relationship between the public and private ICT sectors, and also between the Pacific Islands Telecommunications Association (PITA), the Pacific Islands Internet Society, the Pacific Chambers of Commerce and the Regional Private Sector Organisation (RPSO). As private investments in the PICs' IT infrastructure increases, the PIIPP's vision of "information and communication technology for every Pacific Islander" (PIFS 2002, p.2) may come within reach. This should be given top priority by the leaders of this region, because only when all PICs have the IT infrastructure for reliable connectivity can the Pacific unlock the potential of IT resource backed regional integration.

The Internet would become the key source of information on various issues within the South Pacific region. The countries of the region could share and obtain information about each other through the Internet. This sharing of information would be the catalyst to identify synergies between the operations of various countries. This synergy would form the basis for integrating various aspects of their operations using the Internet as the key facilitation and communication tool. This situation is so because one of the key factors that deter sharing of information and ideas is the lack of knowledge and understanding of the operations of the neighbouring countries. Connectivity through Internet would encourage transparency, and with the resultant knowledge sharing, reduce the fears of loss of sovereignty within a regional integration framework. Thus, in today's fragile business environment within the South Pacific, despite the conventional drawbacks of the Internet, it is deemed to be the key resource on which to renew the regions' integration initiatives.

Once organisations establish a sustainable and affordable Internet-based IT infrastructure, they would be in a position to leverage modern IT technologies such as the Web 2.0 tools and cloud computing resources. These technologies provide significant opportunities to improve cross-border communication and collaboration. The Web 2.0 tools allow users to interact and collaborate with each other in a social environment (Kane et al., 2009). The results of interacting with these tools are rich communities who are able to contribute proactively to current issues and concerns. While the Web 2.0 tools provide the benefit of allowing users to engage in seamless and transparent communication, cloud computing resources are transforming the way in which applications are developed, used and maintained. Cloud computing refers to the provision of software applications and data storage capacity to communities through the Internet (Greengard, 2010). The providers house and maintain these applications, reducing the burden of software development, software maintenance and data management from application users (Marston et al., 2011).

\section{The South Pacific Region}

The South Pacific, or sometimes also referred to as Oceania is a large and diverse area comprising of many small islands scattered over the largest ocean in the world - The Pacific Ocean. For this study, we define the South Pacific as including countries within the ethnic groups of Melanesia, Polynesia, Micronesia and Australia. Collectively, this region has a total population of over 35 million 
and a total land area of 8.5 million $\mathrm{km}^{2}$ (The United Nations, 2011). With the exception of Australia and New-Zealand, the rest of the countries within the Pacific region are classified as Small Island Developing States (SIDS) (The United Nations, 2011). These economies are characterised by small isolated land masses, low resource base, small but increasing populations, environmental fragility and vulnerability to external shocks (Briguglio, 1995). The economic and environmental vulnerability faced by SIDS poses a significant challenge to achieving long-term sustainable development in the region. Regional integration initiatives are espoused as a potential solution to these issues. Pooling the resources of SIDS with the assistance from Australia and New Zealand will greatly assist the Pacific region adapt to economic and environmental variability. It is also crucial that the Pacific leverage the latest technological advancements that can facilitate cross-border communication and collaboration.

This is especially so as the world is in the midst of a renaissance of IT innovation. The proliferation of IT tools, which facilitate communication and collaboration, is abounding. If leveraged appropriately, the dynamic capabilities embodied in these technologies, can significantly assist SIDS in achieving regional integration. In the South Pacific, the adoption of collaborative technologies has been relatively slow. This is due to the dynamic nature of such technologies and the reservations some have over the relevance and utility of such technologies in the South Pacific. While this resistance maybe understandable, these technologies provide significant opportunities to these SIDS. The South Pacific needs to keep pace with these rapid developments, and needs to embrace modern IT tools to achieve economic progress. Embedding these technologies in the regional integration efforts presents a holistic perspective of the importance of these technologies to developing economies.

\section{Theoretical Framework}

Extant work on regional integration emerges from the functionalism theoretical framework. The functionalist approach sees the various stakeholders as the most significant players in the regional integration efforts (Akpan-Obong et al., 2009). This framework acknowledges the important role of IT in facilitating regional integration, but does not present a solid framework for IT-backed regional integration on its own. Aside, development theories, like the theory of modernisation, also contribute to the development of a framework for IT-backed regional integration. Modernisation theory asserts the need for structural changes to facilitate growth. The dependency theory suggests that underdevelopment is a product of unequal relationship of exchange and dependence that exists between parties to regional integration. We posit that the Internet technologies, and subsequent social networking and cloud computing technologies act as the ideal vehicle to eradicate these inequalities and foster equitable dependence amongst the parties.

The theory of functionalism has the rationale of achieving peaceful relations among warring nation-states. But, with this, a global community emerges through an administrative network that better serves human needs (Pentland, 1973). Technological advances and the functional need to cooperate would drive this administrative network. Functionalism, therefore, provides some tentative explanation of how IT might enhance an understanding of regional economic integration processes. The functionalist perspective assumes that the most significant actors are citizens who, in utilising networks of communication and transportation, cooperate and integrate the systems across borders. A functionalist approach also facilitates an examination of integrative schemes aimed at infrastructure development. It can transcend infrastructure to reflect the ways in which citizens and groups interact to achieve and utilise the expected outcomes of integrative schemes. These outcomes are not possible without a communication infrastructure that promotes sharing of knowledge. While this 
approach recognises the role of IT tools like the Internet and Web 2.0 tools, it does not relay how we could utilise these tools to achieve the expected outcomes, and importantly sustain such outcomes.

Development theories focus on issues of economic, social, and political development in countries in the periphery (Akpan-Obong et al., 2009). These theories seek to account for the uneven pattern of development worldwide and to recommend measures to overcome underdevelopment (Martinussen, 1997). One such theory, the modernisation theory, considers internal factors in its explanation of underdevelopment and therefore prescribed internal changes to facilitate growth. However, its focus on internal constraints to development overlooked the structure of the international political economy and the processes through which it adversely affected the development efforts (Akpan-Obong et al., 2009). Dependency theory argues that underdevelopment is created by the unequal relationship of exchange and dependence that exists between core countries and those in the periphery (Dos Santos, 1998).

Importantly, amalgamation of the functionalism and development theories provides the ideal framework to suggest a model of IT-backed regional integration for the countries of the South Pacific. The theoretical frameworks focus on intra and inter relationships between the players and resources, and ways in which countries could focus on their competences and resources to develop an integrative pool of resources. However, to sustain this integrative capacity, the players would need to develop and sustain their IT competencies. To do this, the integration partners need to identify the synergy between their IT-related competencies to develop an overall capacity of regional integration. We use this amalgamated theoretical framework to suggest the eventual IT-backed regional integration for the countries of the South Pacific. However, the success of IT-enabled regional integration efforts is dependent upon the existing infrastructure, institutions and ultimately the acceptance of the initiative by the individuals. For this reason, as a first step in suggesting an IT-backed regional integration model for the South Pacific, we investigate the perceptions of the stakeholders on the antecedents of past regional integration failures, and key factors to consider to ensure the success for an ITbacked regional integration in the South Pacific.

\section{Research Design}

A common way to unpacking the diversity of issues involved in regional integration in the South Pacific is to undertake a case study based approach. The case study based approach is used as our study is exploratory in nature (Yin, 1994). The research seeks to explore the complex issues relating to the role of IT, and specifically the Internet, in facilitating regional integration in the South Pacific. Regional integration involves a myriad of actors and stakeholders. The actors include regional organisations, the public sector, the private sector and international donor agencies. To obtain a diversified set of views on past and intended regional integration efforts, we identified and approached fourty contacts from the regional organisations, the public and private sector, and the international funding agencies. We developed this purposeful sampling frame to include organisations from the South Pacific region with interest in financing for capital development, infrastructure development, trade and commerce, telecommunications, and regional human resource management. Twenty-five contacts responded and accepted our interview requests. These twenty-five individuals come from five countries within the Pacific region. We conducted semi-structured interviews that lasted an average of fourty five minutes. Table 1 presents demographic data on the interviewees. Due to the geographic dispersion of the interviewees, we adopted face-to-face, telephone and video conferencing interview methods. An interview schedule was sent to the interviewees beforehand. The questions elicited the interviewees' general views on reasons for hindrances in regional integration in the 
Pacific and perceptions of web based technologies as a potential solution.

We transcribed and analysed the interview data for its thematic content, which involved identification of a number of conceptions relating to possible factors that has hindered past efforts of regional integration in the South Pacific, and opportunities and issues for an IT-backed regional integration infrastructure. The conceptions emerged using the following steps (Dey, 1993). First was the establishment of the unit of analysis, which were the concepts from the interviewee's expressions ranging from a few words to complete sentences. The second step was code attachment, which act as labels on the unit of analysis and represent the conceptions prevalent in that section of text. The third step involved conception categorisation into broader conceptions. These above steps involved an iterative process of reading and analysing the interview transcripts. We also provided copies of the transcribed notes and thematic analysis to the interviewees for verification and additional comments to ensure validity of our analysis.

\begin{tabular}{|c|c|c|c|c|}
\hline $\begin{array}{l}\text { Interviewee } \\
\text { Reference }\end{array}$ & Organisation Type & $\begin{array}{c}\text { Country } \\
\text { No. }\end{array}$ & Age & $\begin{array}{c}\text { Experience } \\
\text { (Years) }\end{array}$ \\
\hline I1. & Regional Body & 1 & 52 & 25 \\
\hline 12. & Government Department & 2 & 48 & 15 \\
\hline 13. & Regional Body & 1 & 26 & 5 \\
\hline 14. & Government Department & 1 & 55 & 26 \\
\hline 15. & Private Sector & 1 & 28 & 7 \\
\hline 16. & Government Department & 1 & 29 & 6 \\
\hline 17. & Private Sector & 2 & 31 & 15 \\
\hline 18. & Government Department & 1 & 49 & 21 \\
\hline 19. & Government Department & 1 & 51 & 18 \\
\hline I10. & Government Department & 1 & 54 & 23 \\
\hline I11. & Private Sector & 1 & 35 & 16 \\
\hline I12. & Government Department & 3 & 39 & 16 \\
\hline I13. & Regional Body & 3 & 38 & 13 \\
\hline I14. & Regional Body & 1 & 46 & 19 \\
\hline I15. & Government Body & 1 & 25 & 4 \\
\hline I16. & Regional Body & 4 & 41 & 12 \\
\hline I17. & Government Department & 4 & 40 & 15 \\
\hline I18. & Private Sector & 1 & 31 & 10 \\
\hline I19. & Private Sector & 1 & 23 & 2 \\
\hline 120. & Regional Body & 5 & 63 & 33 \\
\hline 121. & Regional Body & 5 & 36 & 15 \\
\hline 122. & Private Sector & 1 & 35 & 12 \\
\hline 123. & Government Department & 1 & 27 & 5 \\
\hline 124. & Private Sector & 1 & 32 & 11 \\
\hline 125. & Private Sector & 1 & 27 & 6 \\
\hline
\end{tabular}

\section{Results and Discussion}

The purpose of the case study based approach was to obtain a deeper understanding of the antecedents of current state of regional integration in the South Pacific. We also wished to obtain perceptions of the key stakeholders on the opportunities and challenges of regional integration on an IT-backed infrastructure. This information will complement our theoretical framework to suggest a model of regional integration on an IT-backed infrastructure for the South Pacific. Table 2 presents the key issues relating to 
difficulties of past regional integration efforts in the South Pacific.

\begin{tabular}{|l|l|}
\hline \multicolumn{2}{|l|}{ Table 2 - Antecedents of past Regional Integration Failures } \\
\hline $\begin{array}{l}\text { Broad } \\
\text { Antecedents }\end{array}$ & Key Themes \\
\hline $\begin{array}{l}\text { Impeding IT } \\
\text { Infrastructure }\end{array}$ & $\begin{array}{l}\text { Infrastructure Development, ICT Resources, Networking } \\
\text { Development, , Technical Support, Broadband Access, } \\
\text { Connectivity, Financing }\end{array}$ \\
\hline $\begin{array}{l}\text { Marginal Human IT } \\
\text { Skills }\end{array}$ & $\begin{array}{l}\text { Brain Drain, Administrative Bureaucracy, Capacity Building, } \\
\text { Technical Knowledge Management, Human Resources, } \\
\text { Change Management, Succession Planning }\end{array}$ \\
\hline $\begin{array}{l}\text { Disparity in Level } \\
\text { of Development }\end{array}$ & $\begin{array}{l}\text { National Agendas, Budget Constraints, Disparate IT } \\
\text { Standards, Network Access, Cost of Communication, Internet } \\
\text { Coverage, Connectivity }\end{array}$ \\
\hline $\begin{array}{l}\text { Monopolised } \\
\text { Communication } \\
\text { Infrastructure }\end{array}$ & $\begin{array}{l}\text { High Internet Cost, High Communication Cost, Limited } \\
\text { Bandwidth, Government Control, ICT Monopoly, Market } \\
\text { Liberalisation }\end{array}$ \\
\hline Frail Political Will & $\begin{array}{l}\text { National \& Regional ICT Policies, ICT Legislations, ICT } \\
\text { Regulatory Framework, Leadership, Partnership, } \\
\text { Governance, Coordination }\end{array}$ \\
\hline
\end{tabular}

We discuss these key issues relating to regional integration failures, and link this to stakeholders' perceptions on the opportunities and challenges of regional integration on an IT-backed infrastructure.

\section{Impeding IT Infrastructure}

A common concern raised by the interviewees was the lack of a viable and sustainable IT infrastructure in many SIDS. In the context of this study, IT infrastructure encompasses the hardware, software and the human components of the system. This problem has been discussed widely in extant literature as a major hindering factor in advancing IT related developments amongst developing countries. Parallel to the survey by the Pacific Island Forum Secretariat (PIFS) in 2002, majority of the interviewees believed that the current status of IT infrastructure is the major hindrance to achieving integration (PIFS, 2002). The characteristics of SIDS such as small land masses, remote locations and environmental fragility require an infrastructure strong enough to withstand its environmental variability, but at the same time flexible enough to adapt to changing technologies. The interviewees saw good potential in the web-based technologies, especially the ready nature of the cloud computing technologies. But, they also indicated that there is a need to establish a grounded Internet infrastructure to access the web-based resources.

Some interviewees shared the following:

"One of the difficulties of achieving regional integration in the Pacific was the fact that the Pacific consists of thousands of small islands spread over a vast area of water. Landlocked regions such as EU and Africa have been able to accomplish integration more quickly as land based ICT infrastructure was easier, faster and cheaper. The Pacific has had to adopt a different approach. Currently, underwater cables are being laid under the Pacific Ocean and will pass through a number of Pacific countries." 121

"The essence of integration is networking. Fiji is in a good position because of the Southern Cross cable that passes through Fiji to Hawaii and private companies providing wireless networks all over Fiji. It's the small islands such as Tokelau, Palau and Niue who only have access to networks with limited bandwidth that face problems. 
Prasad et al.: Faciltating Regional Intergration and Economic Development with Collaborative Technologies

Faciltating Regional Intergration and Economic Development with Collaborative Technologies / Acklesh et al.

Until all countries in the region are on an equal playing field can regional integration efforts really get moving" I14

"Fundamentally, IT infrastructure apart from funding is an underpinning issue of integration. Integration is impossible without the necessary hardware, applications, systems, etc. If you compare ours to Singapore, we are very behind. Still a lot of improvement is needed at each country level before we start talking on a regional level" I4

"Full scale integration might be a long way off for us here in the Pacific. Apart from the status of IT development in each country, there seem to be a lack of coherent push towards a regional infrastructure for ICT as countries seems to be pushing for their own infrastructure development" 122

A strong and resilient infrastructure is especially important for web based applications. One interviewee shared the following regarding the success of cloud computing in the Pacific:

"Yes, I think cloud computing is great! But in order for cloud computing to work we need continual and a resilient network system. If something was to happen to that connection then [my organisation's] internet access would be affected. Because once the network is disrupted all cloud services are also disrupted."I7

\section{Marginal Human IT Skills}

The current status of IT infrastructure in the SIDS is directly related to the lack of human resources with technical IT skills. This assertion is supported by the (PIFS, 2002) when it highlighted that users lack knowledge in operating IT equipment and do not recognise the value of the IT systems. This problem is further exacerbated by the increasing rate of brain drain, where qualified personnel tend to opt for better opportunities in developed countries such as Australia and New Zealand. While the use of IT tools at a personal level is common in some developing economies, the same value of IT is not mirrored in organisational and national settings. There is a significant lag in radically reengineering business processes with modern IT tools at the organisational level, and this situation puts promising IT professionals in a valuable situation. This situation makes them opt for greener pastures abroad. This presents significant hindrance in establishing a national human IT skills capacity. Some interviewees shared the following:

"In the Pacific there is a significant shortage of qualified and skilled ICT personnel. Most major projects are given to external consultants. However, once they complete the project, they get paid; they go back to their countries and forget about us. They don't train the people well enough on how to use and maintain the system. Inevitably the system will fail." I13

"The problem in this region is bureaucracy. Operational level staffs remain there forever, and are hardly promoted to the higher level. Technicians remain technicians, this people should be engineers in the future. This is also a problem contributing to the lack of qualified personnel in IT. There is no defined motivation for trainee or capacity building in IT". 120

\section{Disparity in Level of Development}

Interviewees also noted that the varying level of development amongst SIDS is another hindering factor for regional integration. Mackie et al. (2010) noted that regional priorities are defined by member States and some countries might not consider regional strategies as a national priority. This is also true in the Pacific context as different SIDS are confronted with different budgetary constraints which need urgent attention, thus postponing the need for regional integration for later (PIFS, 2002). The interviewees shared that:

"...integration is something that can be pushed but infrastructure development is at different paces. Fiji for example is ahead of a few countries. I am saying that there needs to be a level playing field, cohesive 
Facilitating Regional Integration and Economic Development with Collaborative Technologies / Acklesh et al.

cooperation to provide a common standard across the region." 14

"There is a huge gap and variety of gaps existing amongst SIDS. A good example is the network infrastructure. Fiji and Samoa are the only two countries using $4 G$ while most are still on $2 G$ networks. So gaps exists depending on the PIC you are referring to." I16

There is also evidence of a general lack of awareness of the value of IT amongst Pacific islanders (PIFS, 2002). This problem is both evident at national as well as the community level. Governments of SIDS like many other developing countries fail to acknowledge the value of IT in development (Boon, 1992). A report by the University of the South Pacific (USP) clearly indicates that many SIDS failed to appropriately incorporate information and communication technologies (ICT) in the primary and secondary curriculum resulting in the lack of awareness and support for ICT developments (USP, 2005).

The cost of facilitating the 'proper environment' for integration is a major concern for SIDS. The benefits of regional integration are widely acknowledged at the national level. The challenges however lie in the short term costs. Examples include loss of fiscal revenues and potential job losses due to market liberalisation may discourage commitments from countries (Mackie et al., 2010). In addition the cost to access information is very expensive in the SIDS as compared to other regions (PIFS, 2002). An interviewee shared the following:

"There will be major upfront costs such as laying cables, leasing, and satellite costs and then you have equipment costs, the application costs, and recurrent costs in terms of training and resourcing appropriate level. It is massive and many SIDS are going to struggle to meet these costs." I17

\section{Monopolised Communication Infrastructure}

Market liberalisation of the information and telecommunications sector is also needed for integration according to the interviewees and this is consistent with the recommendation by the PIFS (2002) study. Majority of the SIDS telecommunication markets are still dominated by government owned entities that monopolise the ICT industries. One interviewee shared the following:

"Other than Fiji, majority of the PICs have undertaken minimal or no effort to deregulate their ICT sectors. Some PICs like Nauru, Tokelau, Niue do not have the capacity to deregulate their ICT sector because of their small population sizes. "T21

In addition, there is also a genuine concern that the problem of a true competitive market does not really exist. While the rationale for monopolised markets in developing economies may be economically justified, this setting does impede potential IT-related growth and development opportunities. Furthermore, private sector organisations that monopolise the market may become too powerful and difficult to manage. Some interviewees felt that some of these organisations were pushing their own agenda ahead of the interests of the countries they operate in. Two interviewees shared the following:

"The thing that's driving ICT in the region are the Internet Service Providers. Since they have the most money to go around they are the ones leading ICT forums. In some way they are promoting their agenda. Governments tag along as they don't have any defined agendas. I think SIDS should be aware of the region's ICT needs and use their bargaining power to collectively prioritise the areas they need to look at." I18

"It is common for Internet Providers to be part of the national IT development process but they always manage to twist the agendas to favour them so the whole process is about spending money and not really how IT can change peoples' lives." T17

\section{Frail Political Will}

Lack of a strong political inhibits the translation of regional commitments and 
Prasad et al.: Faciltating Regional Intergration and Economic Development with Collaborative Technologies

Faciltating Regional Intergration and Economic Development with Collaborative Technologies / Acklesh et al.

priorities into action. There seems to be consensus that country level issues undermine the potential of regional integration (Mackie et al., 2010). South Pacific countries are still strongly embroiled in national sovereignty issues, which conflicts with the collaborative intent of regional integration. Aside, lack of formal IT policies and regulations amongst SIDS reflects the lack of political legitimacy and mandate to enforce ICT commitments amongst members. An interviewee suggested that:

"We have a major political problem when it comes to implementing IT initiatives in SIDS. We need a very strong message coming from the Prime Minister or whoever is in charge in sending the message that this is what we are going to do. Political linkage is important, if its lacking then it will be problematic, thus political commitment is extremely important." 16

Some interviewees also felt that the commitment of the government towards ICT depends on where the ICT ministerial department is located in the country. For some PICs the ICT department is a separate department by itself such as in the case of Fiji. In other PICs the ICT agency is subsumed under a ministry. For instance, in the Solomon Islands it is under the Treasury Department or Ministry of Finance. This is also the same in Vanuatu; however one interviewee stated that the Vanuatu ICT department will be soon moving to the Prime Minister's office. He had this to say about the significance of this move:

"I believe the fact that the ICT department will be moving to the Prime Minister's office provides strong evidence that the government is strongly supporting ICT and e-government initiatives in Vanuatu." I12

Another interviewee had this to share:

"The problem is that governments are very slow in taking ownership of IT initiatives that can significantly improve our recurrent IT problems. We need new leadership that can actually inject changes in the current system." 120

"Forums like the Melanesian Spearhead Group (MSG) and the ICT Ministerial ICT Forums are good forums to discuss regional ICT issues, but right now we need to see more government action and commitment rather than just attending meetings." 120

\section{Summary}

The amalgamated theoretical framework consisting of the functionalism and development theories have informed us on how to leverage IT resources to facilitate regional integration. However, literature and theory provide inadequate guidance on the specific mechanics of leveraging modern web based technologies to facilitate regional integration in the South Pacific context. The case study approach affords the opportunity to obtain a deeper understanding of the environmental and contextual factors through the eyes of the actors and stakeholders. From this understanding, and complementing this to our theoretical framework, an appropriate regional integration model could be designed to embed IT-based solutions in these environments. Interviews with the main stakeholders involved in regional integration initiatives present the antecedents of the current health of regional integration in the South Pacific.

The main antecedents of unsuccessful regional integration efforts related to issues such as the poor IT infrastructure, the difference in the level of IT development amongst SIDS and the lack of awareness at both national and community levels. Government ICT agendas lack the need for investment in IT for proactive management of national and regional issues. Inadequate human IT capital, and continuous brain drain of IT professionals at the organisational and community level results in lack of appreciation and leverage of the invested IT resources. Monopolised telecommunication sectors also impede ITrelated development at all levels. Governments continually fail to recognise 
the potential of liberalised markets with strong private sector involvement as a vehicle to enhance IT developments in their countries. Issues of higher utility costs from linearisation would be cushioned by the availability of generic web-based digital communication tools.

Finally, the lack of political will and support has also been identified as a contributing factor that inhibits the transformation of regional initiatives into reality. A national agenda that builds into regional economic wellbeing is required to promote regional integration initiatives. Aside, the interviewees seem not concerned about security issues relating to increased focus on digital measures of managing the region. This is in contrast to extant literature which highlights security and privacy as the main concerns when adopting Web 2.0 tools and cloud based technologies. The lack of IT security concerns might be related to the lack of awareness and policies at the national level. To date, Tonga is the only country in the South Pacific with a legislation on cybercrime (Burese, 2012). From the preceding discussion and analysis, we suggest the following factors as key enablers of regional integration on an ITenabled infrastructure.

\section{Table 3. Key Factors for Regional Integration 2.0}

Enabling IT Infrastructure

Equitable IT Development in the Region

Greater Awareness on the Potential of the Modern IT Resources

Market Liberalisation of the Information and Telecommunications Sector

Greater Political Support for IT initiatives in building a national and regional IT

infrastructure.

\section{Conclusion}

The Internet and today's collaborative IT resources present a great opportunity to radically transform the collaborative platforms at the organisational, national and regional levels. Regional integration has proved useful in Europe, and the Caribbean (Dion, 2004). Much of their success stems from appropriate deployment of IT resources to foster open and transparent communication and collaboration platforms. Current global economic condition presents a compelling need for smaller developing economies to pool and share resources to manage the unpredictable shocks of the global economy. The study's theories suggest that building IT-related capabilities and integrating IT-related capabilities between regional partners will create synergistic benefits. Thus, the IT resources can act as a key facilitator of regional integration. However, the implementation of IT-based solution must take into account the context of the environment in which the ITbased solution will be implemented in. Employing a case study based approach, this study presents the key antecedents that have led to the past failures of regional integration initiatives in the South Pacific. These antecedents have emerged from rigorous analysis of interview transcripts of actors and stakeholders of regional integration in the South Pacific. The study has also identified five enabling factors for successful IT-backed regional integration for the South Pacific. These findings will aid towards development of a regional integration model on IT-backed infrastructure. This model could aid regional organisations and international organisations that fund IT and regional integration initiatives better identify the areas that need to be addressed to leverage current IT innovations to facilitate IT resource backed regional integration in the South Pacific. 
Prasad et al.: Faciltating Regional Intergration and Economic Development with Collaborative Technologies

Faciltating Regional Intergration and Economic Development with Collaborative Technologies / Acklesh et al.

\section{References}

Akpan-Obong, P., and Parmentier, M.(2009). "Linkages and Connections: A Framework for Research in Information and Communication Technologies, Regional Integration, and Development," Review of Policy Research (26:3), pp.289.

Boon, J. A.(1992). "Information and development: some reasons for failures," The Information Society (8:4), pp.227-241.

Briguglio, L.(1995). "Small island developing states and their economic vulnerabilities," World development (23:9), pp.1615-1632.

Burese, I. (2012). "Cyber crime threat", The Fiji Times, April 25, 2013.

Dey, I. (1993). Qualitative Data Analysis: A User-Friendly Guide for Social Scientists, Routledge: London.

Dion, D.-P. (2004). "Regional integration and economic development: A theoretical approach," Governance and Efficiency of Economic System, Discussion Paper No 20, Retrieved from http://epub.ub.unimuenchen.de/13528/1/20.pdf on April 24, 2013.

Dos Santos, T. (1998). "The structure of dependence," in Development and underdevelopment: The political economy of global inequality, M. A. M. A. Seligson and J. T. PasséSmith (eds.), Lynne Reiner: Boulder, CO, pp.251--261.

Foroutan, F. (1993). "Regional integration in Sub-Saharan Africa: past experience and future prospects," New dimensions in regional integration), pp. 305-335.

Gnansounou, E., Bayem, H., Bednyagin, D., and Dong, J. (2007). "Strategies for regional integration of electricity supply in West Africa," Energy Policy (35:8), pp.41424153.

Greengard, S. (2010). "Cloud computing and developing nations," Communications of the ACM (53:5), pp.18-20.

Kane, G. C., and Fichman, R. G. (2009). "The Shoemaker's Children: Using Wikis for Information Systems Teaching, Research, and Publication (includes Comments and Editoria Note)," Management Information Systems Quarterly (33:1) March 1, pp.1-22.

Lee, H., Owen, R. F., and van der Mensbrugghe, D. (2009). "Regional integration in Asia and its effects on the EU and North America," Journal of Asian Economics (20:3), pp.240254.

Mackie, J., Bilal, S., Ramdoo, I., Hohmeister, H., and Luckho, T. (2010). "Joining Up Africa: Support to Regional Integration.," Discussion Paper.No 99. European Center for Development Policy Management.

Marston, S., Li, Z., Bandyopadhyay, S., Zhang, J., and Ghalsasi, A. (2011). "Cloud computing-The business perspective," Decision Support Systems (51:1), pp. 176-189.

Martinussen, J. (1997). Society, state and market: A guide to competing theories of development, Zed Books: Atlantic Highlands, NJ.

Matthews, N. (2012). "Internet Access Affordability in the Pacific Islands," Retrieved from http://www.strategies.nzl.com/wpape rs/2012014.html on April 22, 2013. 
Pacific Islands Forum Secretariat (2002). "Pacific ICT Capacity and Prospects," Working Paper.

Pacific Islands Forum Secretariat (2007). "The Pacific Plan for Strengthening Regional Cooperation and Integration."

Pentland, C. (1973). "International theory and European integration", The Free Press: New York.

Powell, P. T. (2005). "'“Too Young to Marry": economic convergence and the case against the integration of Pacific states," Pacific Islands regional integration and governance, pp.218239.

Schiff, M. W., and Winters, L. A. (2003). Regional integration and development, A World Bank Publication.
The United Nations (2011). "Composition of macro geographical (continental) regions, geographical sub-regions, and selected economic and other groupings", Retrieved from http://unstats.un.org/unsd/methods/ m49/m49regin.htm on April 27, 2013.

The World Bank (2009). "Swimming Against The Tide: How Developing Countries Are Coping With The Global Crisis,"pp.1-20.

USP. (2005)."ICT in Secondary Education in the Pacific Region: Status, Trends and Prospects", pp.1-96.

Yin, R. K. (1994). Case Study Research: Design and Methods, (2nd ed.) Sage Publications: Thousand Oaks, CA. 
Prasad et al.: Faciltating Regional Intergration and Economic Development with Collaborative Technologies

Faciltating Regional Intergration and Economic Development with Collaborative Technologies / Acklesh et al.

\section{About Authors}

Acklesh Prasad is Lecturer in Business Information Systems at Queensland University of Technology. His research interests and expertise are in the area of fit of Information Technology (IT) to the business processes and ways to measure the value of investments in IT, and governance of IT resources in various organizational settings. His research spans both the theoretical and practical aspects of these issues. He has published widely in these areas in Journals as the Journal of Information Systems, International Journal of Accounting Information Systems, and the Australasian Journal of Information Systems.

Glen Finau is currently a post graduate research student in the School of Accounting and Finance at the University of the South Pacific. He has an undergraduate degree in Accounting and Information Systems and Post graduate Diploma in Accounting. His research interests include IT Business Value creation, e-government and ICT issues in the Pacific. He is also a full member of CPA Australia and the Fiji Institute of Accountants.

Jale Samuwai is currently a post graduate research student in the School of Accounting and Finance at the University of the South Pacific. He has an undergraduate degree in Accounting and Information Systems and Post graduate Diploma in Accounting. His research interests include how information technologies can create and contribute to value creation in small developing economies, particularly in the area of IT Governance.

Biman Prasad is currently Professor of Economics at the University of the South Pacific and Chair of the Oceania Development Network. Professor Prasad served as the Dean of the Faculty of Business and Economics and Head of
School of Economics from 2003 to 2011 at the University of the South Pacific. He has published several books and numerous journal articles on trade and development issues in the Pacific region. Professor Prasad has provided consultancy services to various international development agencies and governments in the Pacific region. He is an Associate Editor of the Journal of Fijian Studies and the Editor-inChief of the Journal of Pacific Studies. He has been a visiting Professor at the Kagoshima University, the Otago University, James Cook University and Jawaharlal Nehru University. He is currently a visiting Professor at the University of Gujarat and holds two adjunct Professorial Appointments at the Griffith University and James Cook University.

Peter F. Green is Professor of Electronic Commerce and Business Information Systems and cluster leader in the UQ Business School at the University of Queensland. Peter has researched, presented, and published widely on systems analysis and design, conceptual modelling, information systems auditing, and eCommerce. His publications have appeared in such internationally refereed journals as MIS Quarterly, Journal of Information Systems, International Journal of Accounting Information Systems, European Journal of Information Systems, Information Systems, IEEE Transactions on Knowledge \& Data Engineering, Journal of Database Management, and the Australian Journal of Information Systems. 